\title{
The presence of aura is not related to changes in the cervical performance and mobility of patients with migraine
}

\section{Gabriela F Carvalho ( $\sim$ gabriela.fisioterapia@gmail.com )}

Ribeirão Preto Medical School/University of São Paulo https://orcid.org/0000-0002-4442-2040

\section{Samuel S Lodovichi}

Universidade de Sao Paulo Faculdade de Medicina de Ribeirao Preto

\section{Carina F Pinheiro}

Universidade de Sao Paulo Faculdade de Medicina de Ribeirao Preto

\section{Mariana T Benatto}

Universidade de Sao Paulo Faculdade de Medicina de Ribeirao Preto

\section{Lidiane L Florencio}

Universidad Rey Juan Carlos Facultad de Ciencias de la Salud

\section{Marcela M Bragatto}

Universidade de Sao Paulo Faculdade de Medicina de Ribeirao Preto

\section{Fabiola Dach}

Universidade de Sao Paulo Faculdade de Medicina de Ribeirao Preto

\section{Debora Bevilaqua-Grossi}

Universidade de Sao Paulo Faculdade de Medicina de Ribeirao Preto

\section{Research article}

Keywords: migraine, aura, dizziness, range of motion, neck pain

Posted Date: July 20th, 2020

DOI: https://doi.org/10.21203/rs.3.rs-42272/v1

License: (1) This work is licensed under a Creative Commons Attribution 4.0 International License. Read Full License

Version of Record: A version of this preprint was published at Musculoskeletal Science and Practice on February 1st, 2021. See the published version at https://doi.org/10.1016/j.msksp.2020.102306. 


\section{Abstract}

Background: Migraine is related to musculoskeletal impairment of the neck and the chronicity of migraine is related to greater disability levels. However, it is not known if other forms of migraine, such as migraine with aura, is related to a different pattern of neck impairment.

Objective: To assess the musculoskeletal and clinical aspects of the neck in patients with migraine with and without aura.

Methods: Up to 125 consecutive patients diagnosed with migraine according to the ICHD-III were recruited from a tertiary headache clinic. Patients were classified by the presence of aura into two groups: migraine with aura (MA, n=37) and migraine without aura (MoA, n=88). The self-report of neck pain was assessed and patients completed the Neck Disability Index (NDI) questionnaire. Furthermore, patients performed the Flexion Rotation Test (FRT) and the Cranio-Cervical Flexion Test (CCFT). Results of all outcomes were contrasted between groups through Mann-Whitney and Qui-square tests.

Results: There was no association between the presence of aura and self-report of neck pain $\left(x^{2}: 1.32\right.$, $p=0.25$ ). No differences were verified between groups regarding presence of neck disability (MA: 10.73, SD: 6.22; MoA: 9.63, SD:8.13, $p=0.25)$ or disability severity $\left(x^{2}=6.17, p=0.10\right)$. Groups did not differ regarding the FRT (MA: $35.07^{\circ}$, SD: 7.90 and MoA: $34.60^{\circ}$, SD: 8.70, $t=-0.22, p=0.83$ ) and there was no association between positive FRT and presence of aura $\left(x^{2}=3.35, p=0.07\right)$. The CCFT did not demonstrate differences among the two groups either $\left(x^{2}=1.65, p=0.80\right)$.

Conclusion: There is no association between migraine aura and presence or disability of neck pain, reduced superior cervical mobility or reduced neck performance. It is expected to find similar neck profile during the clinical assessment of patients with migraine with and without aura.

\section{Introduction}

The presence of pain and dysfunction in the cervical area are often verified in patients with migraine. ${ }^{1-4}$ Evidence has shown that these patients present a reduction of the cervical range of motion, ${ }^{4-8}$ motor control alterations and changes in the performance of the cervical muscles. ${ }^{9,} 10$ However these aspects may not be equally observed for all migraineurs. It is established that patients with chronic migraine present a greater prevalence of neck dysfunction including articular, muscular and sensitivity aspects compared to episodic migraine. , 8-10 $^{-10}$

According to the International Headache Society, ${ }^{11}$ migraine can also be classified according to the presence of aura. This phenomena is present in one-third of the patients, preceding or accompanying a migraine attack. ${ }^{11,12}$ Some authors claim that migraine with aura can be considered a distinct entity, ${ }^{13,14}$ however it is not considered a consensus. ${ }^{15-18}$ But still and all, it is verified in patients with aura some additional comorbidities in comparison to those without aura. Patients with aura present alterations in 
the neuromuscular transmission, ${ }^{19}$ greater prevalence of ischemic-like lesions, functional and structural changes in the brain. ${ }^{17,20-22}$ Patients with and without aura may respond differently to migraine therapy, and those with aura present higher anxiety and depression levels. ${ }^{17,18,23}$ Furthermore, the aura is also associated with cutaneous and visual allodynia, ${ }^{24,25}$ balance control deficits, ${ }^{26,27}$ and with the presence of vestibular symptoms. ${ }^{27,28}$

However, to the best of our knowledge, the differences between migraine with and without aura regarding neck pain and dysfunction have not been studied so far. It is already established that balance deficits and vestibular symptoms are frequently linked to neck pain, ${ }^{29-31}$ muscle fatigue, ${ }^{32-35}$ reduced range of motion ${ }^{36}$ and to dysfunction of the superior cervical joints. ${ }^{35}$ Since patients with aura present balance dysfunction and vestibular symptoms in comparison to patients without aura; and the neck plays a relevant role in the postural control, it can be hypothesized that patients with aura may present greater cervical impairment. Therefore, the aim of this study was to investigate if the presence of aura is related to a greater impairment of the superior cervical range of the motion, decrement of neck muscles performance and greater self-report and impairment of neck pain, compared to patients with migraine without aura.

\section{Methods}

\section{Sample}

Between November 2016 and July 2017, 159 consecutive patients were screened for this cross-sectional study from a university based tertiary headache clinic in Ribeirão Preto, Brazil. It was included in the study males and females between the ages 18 and 55, diagnosed by neurologists specialists in headache according to the International Classification of Headache Disorders (ICHD-III). ${ }^{11}$

Exclusion criteria encompassed any of the following: self-report of neck injury/trauma, patients who have undergone cervical/cranial nerve block in the past three months, pregnancy, history of infection, with a migraine attack during the assessment, diagnosis of other concomitant headaches, and patients with any other rheumatic or chronic disease such as fibromyalgia, neuralgias or self-report of vestibular disease.

Among the 159 patients, 34 (21.3\%) were excluded due to presence of concomitant headache diagnosis $(n=12,7.5 \%)$, fibromyalgia, diabetes and psychiatric disorders $(n=10 ; 6.2 \%)$, and abortive medication overuse $(n=5 ; 3.1 \%)$. Furthermore, 7 patients $(4.4 \%)$ were additionally excluded for not completing all the assessment procedures required for this study. Therefore, 125 subjects were included in this study and allocated in one of the two groups: migraine without aura (MoA, $n=88$ ) and migraine with aura (MA, $\mathrm{n}=37$ ) (Figure 1). This study was approved by the Local Ethics Committee (process num.: 16692/2012) and all patients provided written consent before the data collection.

\section{Procedures}


Initially, subjects filled a structured questionnaire containing general information such as sex, age, headache frequency (days/month), attacks intensity (numeric visual scale, NVS), attack average duration (hours), headache onset (years), self-report of neck pain. Furthermore, they completed the neck disability index (NDI) questionnaire. ${ }^{37}$ The NDI is composed by 10 questions measuring the influence of neck pain on daily activities including personal care aspects, sleep quality and reading, among others. The scores are from 0 to 50 and the patient can be classified in one of the disability levels as follows: mild (5 to 14 points), moderate (15 to 24 points), severe ( 25 to 35 points) and complete disability (36 or more points). ${ }^{37}$

Subsequently, a blinded physiotherapist assessed the patients through two physical tests, the Flexion Rotation Test (FRT) and the Craniocervical Flexion Test (CCFT). Both tests are considered part of a cluster suggested in the assessment of patients with headaches. ${ }^{38}$

The Flexion Rotation Test (FRT) aims to assess the passive range of motion (ROM) of the superior cervical segment (C1-C2). ${ }^{39}$ Patients were instructed to lay on their back, and with maximal flexion of the cervical spine (supported by the assessor), were submitted to a passive rotation for both sides. The ROM was measured by the $\mathrm{CROM}^{\circledR}$ (CROM Performance Attainment Associates, St. Paul, MN, USA). The test was interrupted when the assessor felt a block sensation during the range of motion or when the patients reported pain. A positive test was verified when the ROM was lower than $34^{\circ}, 10^{\circ}$ less than the maximal $\operatorname{ROM}\left(44^{\circ}\right) \cdot{ }^{39,} 40$

The CCFT assesses the neuromotor performance of the deep flexors of the cervical spine (Longus Capitis and Colli). ${ }^{41}$ Patients were instructed to lay on their back and perform an active craniocervical flexion during 10 seconds, monitored by pressure feedback unit - Stabilizer Pressure Biofeedback ${ }^{\circledR}$, Chatanooga, $^{2}$ Hixson, TN, USA. The test is composed by the following 5 progressive stages of pressure, with 10 seconds of duration each one: (1) $20 \mathrm{mmHg}$, (2) $22 \mathrm{mmHg}$, (3) $24 \mathrm{mmHg}$, (4) $28 \mathrm{mmHg}$, and (5) 30 mmHg. ${ }^{41,42}$ Patients performed a familiarization trial before the test in order to ensure the correct performance of the head movement, in order to avoid compensation. The test was interrupted when patients reported pain or demonstrated activation of the superficial flexors of the cervical spine (Sternocleidomastoid and the Anterior Scalene), perceived by the assessor through palpation. ${ }^{42}$

\section{Statistical Analysis}

A priori sample size calculation was performed based on a pilot study with 10 participants in each group. To detect a minimal difference of 6 degrees in the FRT (ES: 0.81), with power of $80 \%$ and $a=5 \%$, it was required a minimum of 24 participants in each group. For a power of $80 \%$ in the detection of stages differences in the CCFT, it was required at least 35 subjects in each group (ES: 0.82). The sample size calculation was performed in the GPower 3.0.10 software.

Descriptive analysis of the data was performed by means of percentage, average and standard derivation (SD). The Shapiro-Wilk test was used to check normal distribution of the data, and it was verified just for 
the FRT outcome ( $p=N S)$.

Prevalence of neck pain among groups were verified through the Qui-square test, and mean scores of the NDI questionnaire were compared by the Mann-Whitney test. The severity categories of both NDI was also compared among groups through the Qui-square test. For the FRT, independent t-Student test was employed to compare the average of groups. The Qui-square test was used to compare the prevalence of a positive FRT test and the stages of the CCFT test among groups. The statistical analysis was performed in the SPSS 20.0 software considering a significance level of $5 \%$.

\section{Results}

The demographic and clinical sample data are presented at Table 1. It was verified greater prevalence of women in both groups ( $M o A, n=72,81.8 \%$; and $M A, n=36,98 \%$ ), with higher proportion in the MA compared to the MoA group $(p=0.02)$. There were no differences between groups regarding age (MA: 36.38, SD: 10.51; MoA: 35.35, SD:10.67, $p=0.69$ ), migraine frequency (MA: 14.34, SD: 9.04; MoA: 14.81, SD: 10.07, $p=0.93$ ), disease onset in years (MA: 12.78, SD: 10.09; MoA: 14.18, SD: 10.00, $p=0.45$ ), migraine intensity (MA: 7.51, SD: 2.74; MoA: 7.54, SD: 3.15, $p=0.57$ ), and attack duration (MA: 17.41, SD: 18.23; MoA: 24.39, SD: 29.75, $p=0.72$ ).

The self-report of neck pain was not associated with the presence of aura $\left(x^{2}: 1.32, p=0.25\right)$. Furthermore, the NDI average score did not differ among groups (MA: 10.73, DP: 6.22 and MoA: 9.63, DP: 8.13, $p=0.25$ ) and the presence of aura was not associated with greater severity of neck impairment, according to the categorical classification of the NDI (NDI: $x^{2}=6.17, p=0.10$, Table 1$)$.

No ROM differences were observed between the MA and MoA groups in the FRT (MA: $35.07^{\circ}$, DP: $7.90^{\circ}$, and MoA: $34.6^{\circ}, \mathrm{DP}: 8.70^{\circ}, \mathrm{t}=-0.21, \mathrm{p}=0.83$ ). The groups also did not present differences regarding the distribution of positive FRT (MA: 48\%, MoA: $64 \%, x^{2}: 3.35, p=0.07$ ) (Table 2). In the CCFT, no association was observed between presence of aura and each test stage: (1) MA 32\%, MoA 23\%; (2) MA 24\%, MoA $33 \%$; (3) MA 24\%, MoA 24\%; (4) MA 8\%, MoA 10\%; (5) MA 11\%, MoA 6.8\% ( $\left.x^{2}=1.65, p=0.80\right)$ (Table 3).

\section{Discussion}

Our findings were opposite to our initial hypothesis, since the presence of aura was not associated with worse neck mobility or poor performance of the cervical muscles. The presence of neck pain and neck disability was not greater in patients with aura either.

Our hypothesis was based on the current evidence of an association between aura and an increased number of comorbidities, including cutaneous allodynia, ${ }^{24}$ balance impairment, and vestibular symptoms, in contrast to patients without aura. ${ }^{26,27,43}$ Among the potential etiologies for developing these particular symptoms, the neck dysfunction and pain are described to have a significant role. ${ }^{29-31,44}$ Neck pain, ${ }^{31}$ muscle fatigue, ${ }^{32-34}$ trigger points, ${ }^{34}$ and reduced neck range of motion ${ }^{36}$ can be related to 
abnormal afferences arising from the joints and muscle receptors. Therefore, it can potentially drive a mismatch between the neck, vestibular and visual inputs in the Central Nervous System (CNS) ${ }^{30,36}$ The divergent information regarding the head position in relation to the body received by the CNS is often related to postural instability, vestibular symptoms and nystagmus. ${ }^{30,31,36,45}$

In fact, recent studies have demonstrated balance impairment also in patients with idiopathic neck pain ${ }^{31}$ and in patients with headaches related to the neck, such as cervicogenic ${ }^{46}$ and tension-type headache. ${ }^{47-}$ ${ }^{49}$ In this way, we would suppose that the balance impairment demonstrated in patients with aura could be related to a greater neck dysfunction, since neck pain is very prevalent in migraine population ${ }^{1,4,50}$ and the aura is related to an altered neuromuscular transmission. ${ }^{19}$

The absence of differences regarding the neck impairment between groups potentially reveal a small contribution of the peripheric afferences from the neck to the balance instability or vestibular symptoms verified in patients with aura. Indeed, previous studies have suggest that these symptoms may have a central etiology, related to alterations in the cerebellum, ${ }^{51,52}$ vestibular and visual systems. ${ }^{48,49,53-56}$ On the other hand, patients with cervicogenic and tension type headache would present balance alterations due the altered cervical afferent input, in a similar profile of patients with idiopathic neck pain. ${ }^{46,47,49}$

The presence of neck pain in migraineurs is also related to worse clinical presentation, including greater severity of cutaneous allodynia, reduced upper cervical mobility, and worse performance in the Craniocervical Flexion Test. ${ }^{44}$ Despite allodynia is more prevalent in patients with aura, ${ }^{24}$ no differences regarding the remaining outcomes were found.

It is important to highlight that our study did not stratify patients according to the chronicity of migraine frequency, but patients with this condition were distributed equally among both study groups. This design was chosen since our aim was to verify the possible influence of aura on the musculoskeletal neck features. Furthermore, there are already extensive evidence regarding the negative effect of frequency chronicity in migraine patients including greater neck disability ${ }^{10}$ and range of motion reduction, ${ }^{57}$ frequency of allodynia symptoms, ${ }^{58}$ increased activity of superficial neck extensor muscles, ${ }^{9}$ altered muscle performance, ${ }^{59}$ greater prevalence of vestibular symptoms ${ }^{28}$ and balance changes. ${ }^{26}$

Translating into clinical practice, health professionals should consider the chronicity of migraine frequency as an important factor, which would influence results of clinical assessment regarding neck musculoskeletal features, balance tests and vestibular symptoms. However, it is not expected to find greater neck impairment in patients with aura in comparison with migraineurs without aura. Gathering all these study results together, insights for the clinical practice can be drawn and would allow clinicians to propose tailored interventions, increasing the treatments success chances in the management of this disabling condition.

We describe the absence of balance assessment as one limitation of our study, since direct conclusions between presence of aura, neck impairment, and balance changes would be better understood. However, 
previous findings allow us to speculate possible associations among these factors. ${ }^{24-31,35}$ It is important to highlight that these data are from a tertiary headache clinic and differences among distribution of female and males was found in our sample. These aspects may have influenced our results, despite the absence of difference for all outcomes between groups.

Despite the study limitations, to the best our knowledge, this is the first study that explored the influence of aura on the neck symptomatology. Based on reliable tests ${ }^{60,61}$ widely used in the clinical practice, we can suggest that the aura is not related to a greater neck impairment. We believe that it adds to the current literature in the field and would contribute to the decision making in clinical practice.

\section{Conclusion}

Migraine with aura is not associated to the presence and disability related to neck pain, compared to patients without aura. Furthermore, it is also not related to reduced range of motion of the superior cervical segment, neither to lower neck muscular performance. Clinical approach for the migraineurs' neck should take into account individual musculoskeletal features, but not the presence of migraine aura.

\section{Declarations}

Ethical approval: This study was approved by the Ethics Committee from the Clinics Hospital of Ribeirão Preto (process num.: 16692/2012) and all patients provided written consent before the data collection.

Consent for publication: not applicable.

Availability of data and materials: The datasets used and/or analyzed during the current study are available from the corresponding author on reasonable request.

Competing interests: All authors declare no conflict of interests.

Funding: Fapesp Foundation, process number 2015/18031-5.

\section{Authors' contributions}

Conceptualization: GFC; LLF; DBG; FD.

Data curation: SSL; MT; MMB; CFP.

Formal analysis: SSL; GFC; MT; MMB; CFP.

Funding acquisition: DBG; FD.

Methodology: SSL; GFC; LLF; MT; MMB; CFP; DBG; FD.

Supervision: GFC; DBG; FD. 
Writing - original draft: GFC; SSL.

Writing - review \& editing: SSL; GFC; LLF; MT; MMB; CFP; DBG; FD.

\section{Acknowledgements}

The authors thank the Lapomh research group and the Craniofacial Pain Clinic of the Ribeirão Preto Clinics Hospital.

\section{Abbreviations}

CCFT: Cranio-Cervical Flexion Test

FRT: Flexion Rotation Test

ICHD-III: $3^{\text {rd }}$ edition of the International Classification of Headache Disorders

MA: Migraine with aura

MoA: Migraine without aura

NDI: Neck Disability Index

NVS: Numeric visual scale

ROM: Range of motion

\section{References}

1. Calhoun $A H$, Ford S, Millen C, Finkel AG, Truong $Y$, Nie Y. The prevalence of neck pain in migraine. Headache 2010;50:1273-1277.

2. Ashina S, Bendtsen L, Lyngberg AC, Lipton RB, Hajiyeva N, Jensen R. Prevalence of neck pain in migraine and tension-type headache: a population study. Cephalalgia 2015;35:211-219.

3. Carvalho GF, Schwarz A, Szikszay TM, Adamczyk WM, Bevilaqua-Grossi D, Luedtke K. Physical therapy and migraine: musculoskeletal and balance dysfunctions and their relevance for clinical practice. Brazilian journal of physical therapy 2019.

4. Luedtke K, Starke W, May A. Musculoskeletal dysfunction in migraine patients. Cephalalgia 2017:333102417716934.

5. Bevilaqua-Grossi D, Pegoretti KS, Goncalves MC, Speciali JG, Bordini CA, Bigal ME. Cervical mobility in women with migraine. Headache 2009;49:726-731.

6. Ferracini GN, Florencio LL, Dach F, et al. Musculoskeletal disorders of the upper cervical spine in women with episodic or chronic migraine. European journal of physical and rehabilitation medicine 2017;53:342-350. 
7. Luedtke K, May A. Stratifying migraine patients based on dynamic pain provocation over the upper cervical spine. J Headache Pain 2017;18:97.

8. Oliveira-Souza AIS, Florencio LL, Carvalho GF, Fernandez-De-Las-Penas C, Dach F, Bevilaqua-Grossi D. Reduced flexion rotation test in women with chronic and episodic migraine. Brazilian journal of physical therapy 2019.

9. Florencio LL, Oliveira AS, Lemos TW, et al. Patients with chronic, but not episodic, migraine display altered activity of their neck extensor muscles. J Electromyogr Kinesiol 2016;30:66-72.

10. Florencio LL, Chaves TC, Carvalho GF, et al. Neck pain disability is related to the frequency of migraine attacks: a cross-sectional study. Headache 2014;54:1203-1210.

11. Headache Classification Committee of the International Headache Society (IHS) The International Classification of Headache Disorders, 3rd edition. Cephalalgia 2018;38:1-211.

12. Russell MB, Rasmussen BK, Thorvaldsen P, Olesen J. Prevalence and sex-ratio of the subtypes of migraine. International journal of epidemiology 1995;24:612-618.

13. Russell MB, Rasmussen BK, Fenger K, Olesen J. Migraine without aura and migraine with aura are distinct clinical entities: a study of four hundred and eighty-four male and female migraineurs from the general population. Cephalalgia 1996;16:239-245.

14. Kreczmanski P, Wolak T, Lewandowska M, Domitrz I. Altered functional brain imaging in migraine patients: BOLD preliminary study in migraine with and without aura. Neurol Neurochir Pol 2019;53:304-310.

15. Ligthart L, Boomsma DI, Martin NG, Stubbe JH, Nyholt DR. Migraine with aura and migraine without aura are not distinct entities: further evidence from a large Dutch population study. Twin Res Hum Genet 2006;9:54-63.

16. Nyholt DR, Gillespie NG, Heath AC, Merikangas KR, Duffy DL, Martin NG. Latent class and genetic analysis does not support migraine with aura and migraine without aura as separate entities. Genet Epidemiol 2004;26:231-244.

17. Vgontzas A, Burch R. Episodic Migraine With and Without Aura: Key Differences and Implications for Pathophysiology, Management, and Assessing Risks. Curr Pain Headache Rep 2018;22:78.

18. Ball HA, Samaan Z, Brewster S, et al. Depression, migraine with aura and migraine without aura: their familiality and interrelatedness. Cephalalgia 2009;29:848-854.

19. Domitrz I, Kostera-Pruszczyk A, Kwiecinski H. A single-fibre EMG study of neuromuscular transmission in migraine patients. Cephalalgia 2005;25:817-821.

20. Bashir A, Lipton RB, Ashina S, Ashina M. Migraine and structural changes in the brain: A systematic review and meta-analysis. Neurology 2013;81:1260-1268.

21. Russo A, Tessitore A, Silvestro M, et al. Advanced visual network and cerebellar hyperresponsiveness to trigeminal nociception in migraine with aura. J Headache Pain 2019;20:46.

22. Coppola G, Di Lorenzo C, Parisi V, Lisicki M, Serrao M, Pierelli F. Clinical neurophysiology of migraine with aura. J Headache Pain 2019;20:42. 
23. Hansen JM, Charles A. Differences in treatment response between migraine with aura and migraine without aura: lessons from clinical practice and RCTs. J Headache Pain 2019;20:96.

24. Aguggia M. Allodynia and migraine. Neurol Sci 2012;33 Suppl 1:S9-11.

25. Perenboom MJL, Zamanipoor Najafabadi AH, Zielman R, Carpay JA, Ferrari MD. Quantifying visual allodynia across migraine subtypes: the Leiden Visual Sensitivity Scale. Pain 2018;159:2375-2382.

26. Carvalho GF, Bonato P, Florencio LL, et al. Balance Impairments in Different Subgroups of Patients With Migraine. Headache 2017;57:363-374.

27. Carvalho GF, Chaves TC, Dach F, et al. Influence of Migraine and of Migraine Aura on Balance and Mobility - A Controlled Study. Headache 2013;53:1116-1122.

28. Carvalho GF, Vianna-Bell FH, Florencio LL, et al. Presence of vestibular symptoms and related disability in migraine with and without aura and chronic migraine. Cephalalgia 2018:333102418769948.

29. Quek J, Brauer SG, Clark R, Treleaven J. New insights into neck-pain-related postural control using measures of signal frequency and complexity in older adults. Gait Posture 2014;39:1069-1073.

30. Ruhe A, Fejer R, Walker B. Altered postural sway in patients suffering from non-specific neck pain and whiplash associated disorder - A systematic review of the literature. Chiropractic \& manual therapies 2011;19:13.

31. Treleaven J. Sensorimotor disturbances in neck disorders affecting postural stability, head and eye movement control-Part 2: case studies. Manual therapy 2008;13:266-275.

32. Gosselin G, Fagan MJ. The effects of cervical muscle fatigue on balance - a study with elite amateur rugby league players. J Sports Sci Med 2014;13:329-337.

33. Liang Z, Clark R, Bryant A, Quek J, Pua YH. Neck musculature fatigue affects specific frequency bands of postural dynamics during quiet standing. Gait Posture 2014;39:397-403.

34. Otadi K, Hadian MR, Talebian S, Shadmehr A, Emamdoost S, Shahriar G. The effect of myofascial neck pain on postural control: visual deprivation. Journal of back and musculoskeletal rehabilitation 2013;26:375-380.

35. Schieppati M, Nardone A, Schmid M. Neck muscle fatigue affects postural control in man. Neuroscience 2003;121:277-285.

36. Quek JM, Pua YH, Bryant AL, Clark RA. The influence of cervical spine flexion-rotation range-ofmotion asymmetry on postural stability in older adults. Spine (Phila Pa 1976) 2013;38:1648-1655.

37. Cook C, Richardson JK, Braga L, et al. Cross-cultural adaptation and validation of the Brazilian Portuguese version of the Neck Disability Index and Neck Pain and Disability Scale. Spine (Phila Pa 1976) 2006;31:1621-1627.

38. Luedtke K, Boissonnault W, Caspersen N, et al. International consensus on the most useful physical examination tests used by physiotherapists for patients with headache: A Delphi study. Manual therapy 2016;23:17-24. 
39. Ogince M, Hall T, Robinson K, Blackmore AM. The diagnostic validity of the cervical flexion-rotation test in C1/2-related cervicogenic headache. Manual therapy 2007;12:256-262.

40. Hall T, Robinson $\mathrm{K}$. The flexion-rotation test and active cervical mobility-a comparative measurement study in cervicogenic headache. Manual therapy 2004;9:197-202.

41. Jull GA, O'Leary SP, Falla DL. Clinical assessment of the deep cervical flexor muscles: the craniocervical flexion test. Journal of manipulative and physiological therapeutics 2008;31:525-533.

42. Jull G, Falla D. Does increased superficial neck flexor activity in the craniocervical flexion test reflect reduced deep flexor activity in people with neck pain? Manual therapy 2016;25:43-47.

43. Carvalho GF, Almeida CS, Florencio LL, et al. Do patients with migraine experience an increased prevalence of falls and fear of falling? A cross-sectional study. Physiotherapy 2018.

44. Bragatto MM, Bevilaqua-Grossi D, Benatto MT, et al. Is the presence of neck pain associated with more severe clinical presentation in patients with migraine? A cross-sectional study. Cephalalgia 2019:333102419854061.

45. Herdman SJ, Clendaniel RA. Vestibular Rehabilitation, 4th ed. Philadelphia: FA Davis Company, 2014.

46. Sremakaew M, Sungkarat S, Treleaven J, Uthaikhup S. Impaired Standing Balance in Individuals with Cervicogenic Headache and Migraine. J Oral Facial Pain Headache 2018;32:321-328.

47. Giacomini PG, Alessandrini M, Evangelista M, Napolitano B, Lanciani R, Camaioni D. Impaired postural control in patients affected by tension-type headache. Eur J Pain 2004;8:579-583.

48. Ishizaki K, Mori N, Takeshima T, et al. Static stabilometry in patients with migraine and tension-type headache during a headache-free period. Psychiatry Clin Neurosci 2002;56:85-90.

49. Rossi C, Alberti A, Sarchielli P, et al. Balance disorders in headache patients: evaluation by computerized static stabilometry. Acta Neurol Scand 2005;111:407-413.

50. Calhoun AH, Ford S, Pruitt AP. Presence of neck pain may delay migraine treatment. Postgrad Med 2011;123:163-168.

51. Gerwig M, Rauschen L, Gaul C, Katsarava Z, Timmann D. Subclinical cerebellar dysfunction in patients with migraine: evidence from eyeblink conditioning. Cephalalgia 2014;34:904-913.

52. Sandor PS, Mascia A, Seidel L, de Pasqua V, Schoenen J. Subclinical cerebellar impairment in the common types of migraine: a three-dimensional analysis of reaching movements. Ann Neurol 2001;49:668-672.

53. Akdal G, Balci BD, Angin S, Ozturk V, Halmagyi GM. A longitudinal study of balance in migraineurs. Acta Otolaryngol 2012;132:27-32.

54. Ongun N, Atalay NS, Degirmenci E, Sahin F, Bir LS. Tetra-ataxiometric Posturography in Patients with Migrainous Vertigo. Pain physician 2016;19:E87-96.

55. Furman JM, Sparto PJ, Soso M, Marcus D. Vestibular function in migraine-related dizziness: a pilot study. J Vestib Res 2005;15:327-332.

56. Baker BJ, Curtis A, Trueblood P, Vangsnes E. Vestibular functioning and migraine: comparing those with and without vertigo to a normal population. J Laryngol Otol 2013;127:1169-1176. 
57. Carvalho GF, Chaves TC, Goncalves MC, et al. Comparison between neck pain disability and cervical range of motion in patients with episodic and chronic migraine: a cross-sectional study. Journal of manipulative and physiological therapeutics 2014;37:641-646.

58. Benatto MT, Florencio LL, Carvalho GF, et al. Cutaneous allodynia is more frequent in chronic migraine, and its presence and severity seems to be more associated with the duration of the disease. Arq Neuropsiquiatr 2017;75:153-159.

59. Florencio LL, de Oliveira AS, Carvalho GF, et al. Cervical Muscle Strength and Muscle Coactivation During Isometric Contractions in Patients With Migraine: A Cross-Sectional Study. Headache 2015;55:1312-1322.

60. Juul T, Langberg H, Enoch F, Sogaard K. The intra- and inter-rater reliability of five clinical muscle performance tests in patients with and without neck pain. BMC Musculoskelet Disord 2013;14:339.

61. Hall TM, Robinson KW, Fujinawa O, Akasaka K, Pyne EA. Intertester reliability and diagnostic validity of the cervical flexion-rotation test. Journal of manipulative and physiological therapeutics 2008;31:293-300.

\section{Tables}


Table 1. Sample demographic and clinical data represented by percentage (\%) or mean (SD) of patients with migraine with (MA) and without aura (MoA).

MA (n=37) MoA (n=88) $\quad p$

\section{Sex}

Females

$36(97 \%)$

$72(82 \%)$

0.02

Males

$1(3 \%)$

$16(18 \%)$

Age

$36.39(10.51)$

$35.35(10.67)$

0.69

\section{Headache}

Frequency (monthly)

$14.34(9.04)$

$14.81(10.07)$

0.93

Migraine onset (years)

12.78(10.09)

$14.18(10.0)$

0.45

Pain intensity (NPS: 0-10)

$7.51(2.74)$

$7.54(3.15)$

0.58

Pain duration (hours)

$17.41(18.23)$

24.39 (29.75)

0.72

\section{Neck Pain}

Yes

$29(78 \%)$

$60(68 \%)$

0.25

No

$8(22 \%)$

$28(32 \%)$

NDI score

$10.73(6.22)$

$9.63(8.13)$

0.25

NDI classification

No disability

7 (19\%)

$29(33 \%)$

0.10

Mild disability

$21(57 \%)$

35 (40\%)

Moderate disability

9 (24\%)

$18(20.5 \%)$

Severe disability

0

$6(7 \%)$

Complete disability

0

0 
Table 2. FRT results of patients with migraine with (MA) and without aura (MoA).

\begin{tabular}{lcccc}
\hline \multicolumn{1}{c}{ Flexion Rotation Test } & MoA (n=88) & MA (n=37) & $\boldsymbol{p}$ & $\mathbf{x} \square$ \\
\hline FRT degrees (Mean, SD) & $35.07(7.90)$ & $34.6(8.70)$ & 0.83 \\
Positive & $56(64 \%)$ & $20(48 \%)$ & 0.07 & 3.35 \\
Negative & $32(36 \%)$ & $22(52 \%)$ & & \\
\hline
\end{tabular}

FRT: flexion rotation test.

Table 3. CCFT results of patients with migraine with (MA) and without aura (MoA).

\begin{tabular}{cccc}
\hline Stages & MA (n=37) & MoA (n=88) & $p$ \\
\hline $22 \mathrm{mmHg}$ & $12(32 \%)$ & $23(26 \%)$ & 0.80 \\
$24 \mathrm{mmHg}$ & $9(24 \%)$ & $29(33 \%)$ & \\
$26 \mathrm{mmHg}$ & $9(24 \%)$ & $21(24 \%)$ & \\
$28 \mathrm{mmHg}$ & $3(8 \%)$ & $9(10 \%)$ & \\
$30 \mathrm{mmHg}$ & $4(11 \%)$ & $6(6.8 \%)$ &
\end{tabular}

CCFT: craniocervical flexion test.

\section{Figures}




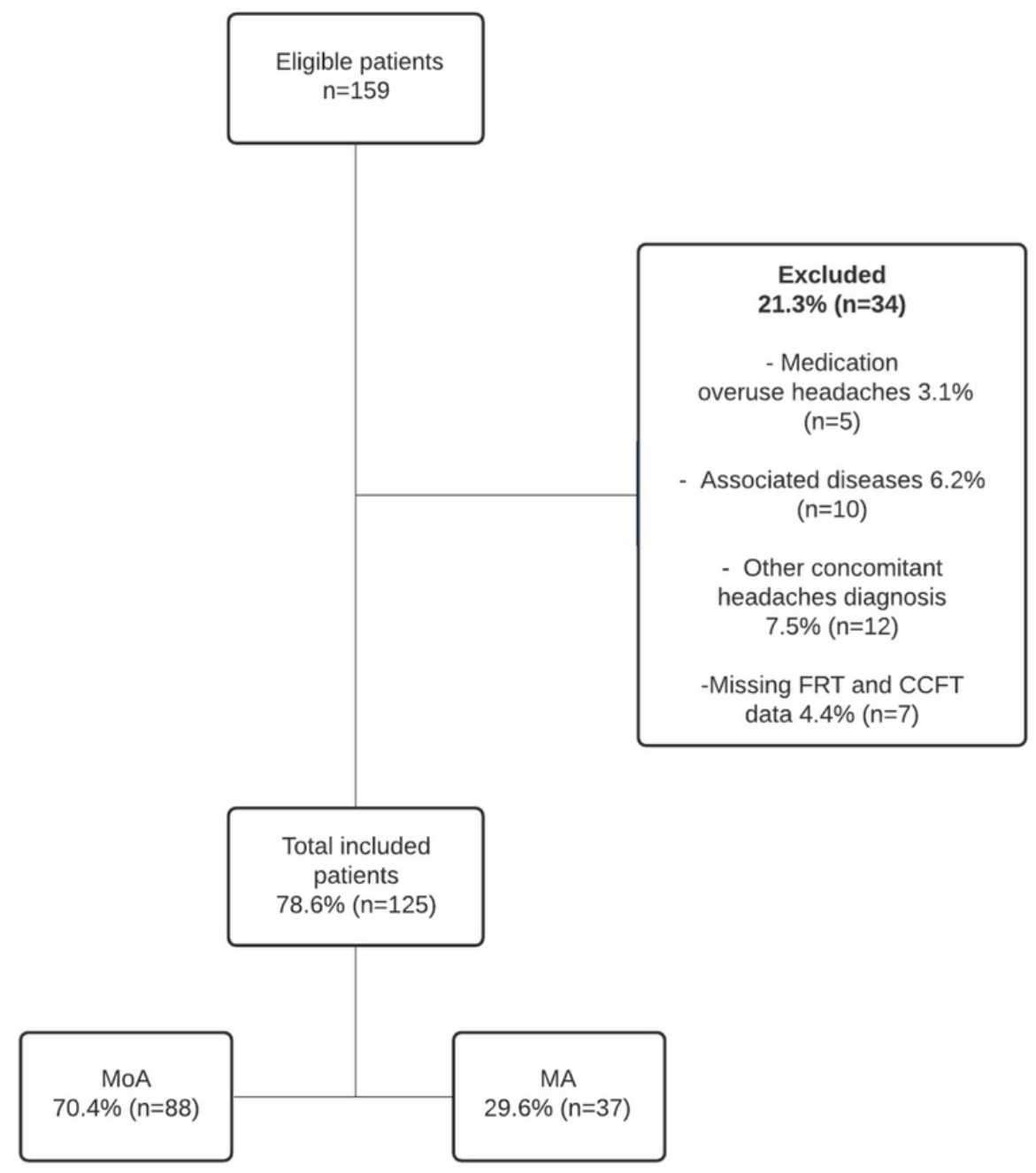

Figure 1

Figure 1. Flow diagram of the sample selection.

\section{Supplementary Files}

This is a list of supplementary files associated with this preprint. Click to download.

- hedstrobechecklist.doc

- hedstrobechecklist.doc 